\title{
Agôn
}

HS 1 | 2011

Mettre en scène l'événement

\section{Debout au centre du désastre}

Premiers retours sur l'avant-première de 11 septembre 2001 de Michel Vinaver dans une mise en scène d'Arnaud Meunier - Comédie de SaintÉtienne, 5 septembre 2011

\section{Marion Boudier, Sylvain Diaz et Barbara Métais-Chastanier}

\section{(2) OpenEdition}

Journals

Édition électronique

URL : https://journals.openedition.org/agon/1830

DOI : 10.4000 /agon. 1830

ISSN : 1961-8581

\section{Éditeur}

Association Agôn

\section{Référence électronique}

Marion Boudier, Sylvain Diaz et Barbara Métais-Chastanier, « Debout au centre du désastre », Agôn [En ligne], HS 1 | 2011, mis en ligne le 05 septembre 2011, consulté le 14 juillet 2022. URL : http:// journals.openedition.org/agon/1830; DOI : https://doi.org/10.4000/agon.1830

Ce document a été généré automatiquement le 14 juillet 2022.

Tous droits réservés 


\section{Debout au centre du désastre}

Premiers retours sur l'avant-première de 11 septembre 2001 de Michel Vinaver dans une mise en scène d'Arnaud Meunier - Comédie de SaintÉtienne, 5 septembre 2011

\section{Marion Boudier, Sylvain Diaz et Barbara Métais-Chastanier}

1 Des regards fouillant le vide, des témoins ordinaires derrière des grilles au-dessus des ruines invisibles de Ground Zero : dans son film Carrosserie ${ }^{1}$ (2004), projeté à l'occasion du lancement de ce hors-série le soir de l'avant-première de 11 septembre 2001 à la Comédie de Saint-Étienne, Robert Cantarella met en valeur deux motifs liés aux attentats de New York que l'on retrouve dans les photos d'Olivier Culmann comme dans le spectacle d'Arnaud Meunier : le témoin et le lieu.

\section{Le lieu}

2 Alors que dans Carrosserie, Robert Cantarella adopte une perspective périphérique sur l'événement, en filmant les pourtours du chantier, Arnaud Meunier investit le centre aveugle de Groud Zero.

3 La scénographie, sobre structure métallique rouge vif qui encadre la scène, évoque en effet un espace tendu entre destruction et reconstruction, où certains reconnaîtront les croix des ruines des tours jumelles...

4 Arnaud Meunier ne se résout toutefois pas à cette unique perspective. Il joue au contraire du dedans et du dehors: si les témoignages sont donnés par les lycéens depuis le centre du plateau - le vide -, le journaliste, interprété alternativement par les cinq comédiens professionnels du spectacle, commente l'action depuis les différents niveaux de la structure. Ce point de vue surplombant fait de ces cinq comédiens des témoins de témoins. 
11 septembre 2001 de Michel Vinaver

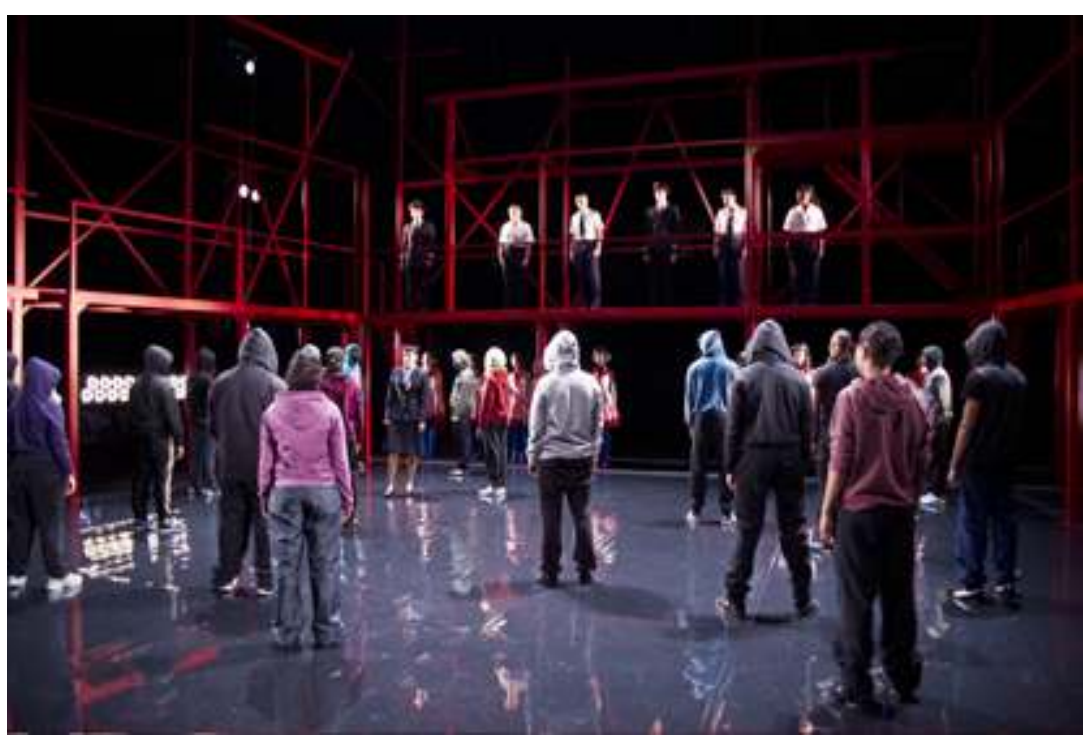

Mise en scène d'Arnaud Meunier, Comédie de Saint-Étienne, septembre 2011

(C) PIERRE-ÉTIENNE VILBERT

\section{Éloge funèbre}

5 La présence, souvent silencieuse, des journalistes invite les spectateurs à écouter d'autant plus attentivement le récit des personnages, tel celui de John Paul DeVito qui semble tout à coup présent face à nous dans le corps d'un lycéen de 17 ans. L'alternance entre témoignages de survivants et commentaires extérieurs de l'événement renforce la touchante oscillation du spectacle entre testimonial et testamentaire.

6 Cette valeur testamentaire est manifeste dans la dimension d'éloge funèbre que prend la mise en scène d'Arnaud Meunier, fonction commémorative d'autant plus assumée que la jeunesse des acteurs crée une mise à distance immédiate, tournée vers l'avenir.

7 Certaines scènes évoquent ainsi les installations de Christian Boltanski travaillant sur la mémoire d'un événement ineffable : vêtements éparpillés au sol, autour duquel le groupe semble se recueillir; photos des lycéens enfants qui défilent sur un triptyque de panneaux blancs composant un retable.

8 La lecture du testament de Mohammed Atta, remarquablement porté par un jeune comédien, sur fond de musique baroque, est aussi un moment fort du spectacle, unissant les deux camps dans la mort.

\section{Images d'une Amérique tendue entre destruction et reconstruction}

9 Le spectacle se referme sur l'image de Bush et Ben Laden, leaders interprétés par deux groupes d'acteurs métissés, en costumes de Gl's ou de militants du Jihad. Symétriquement campés aux deux extrémités de la structure du décor, ils nous font face comme à la proue de deux vaisseaux ennemis, mais semblables. 

« neuf-trois » (jeunes cagoulés rodant, seul ou en bande sous la structure métallique qui s'apparente alors à la cour d'un grand ensemble de banlieue), le spectacle convoque des images de l'Amérique, à commencer par celle, inattendue et plaisante, des «cheerleaders" qui composent le chœur, jeunes femmes vêtues aux couleurs du drapeau américain.

12 C'est dès lors comme une fresque du déclin de l'empire américain que se donne à lire ce spectacle qui met également en scène la tentative des États-Unis pour rebondir à travers un appel à la consommation et la constitution de nouveaux symboles, tel le héros ordinaire Jan Demczur, laveur de carreaux affublé d'une paire d'ailes d'ange à la fin du spectacle. Nouvelle icône d'un monde qui se cherche encore et qui, en vérité, à force d'user des mêmes recettes, peine à se trouver.

\section{1 septembre 2001 de Michel Vinaver}

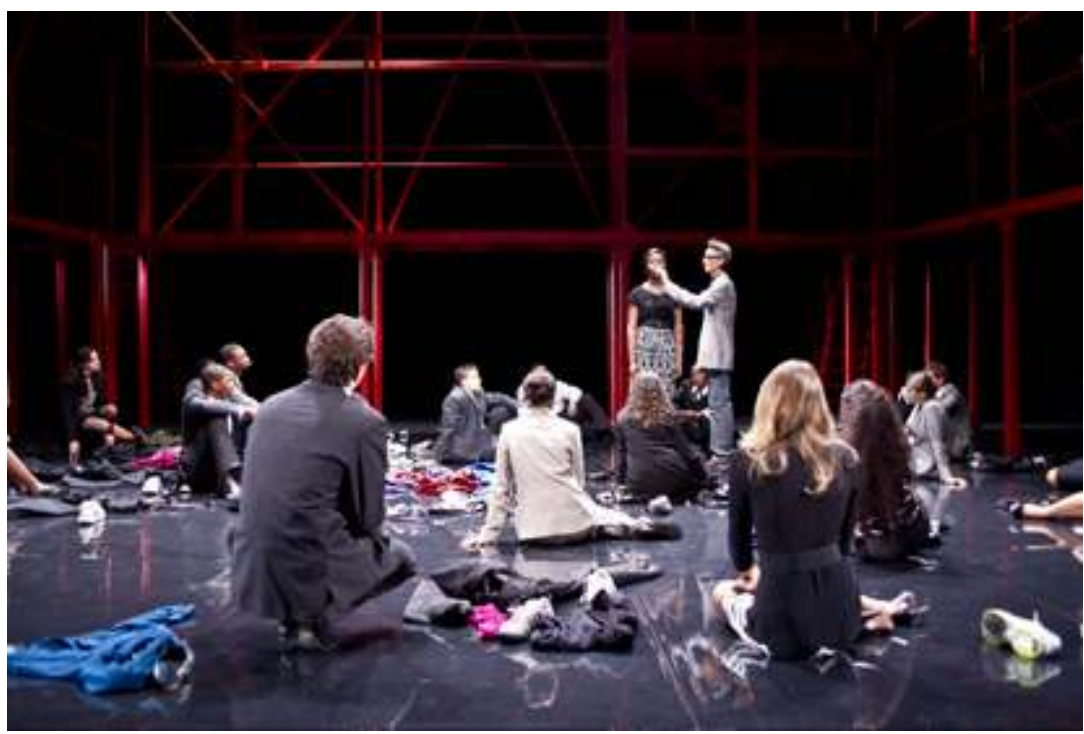

Mise en scène d'Arnaud Meunier, Comédie de Saint-Étienne, septembre 2011

C PIERRE-ÉTIENNE VILBERT

\section{Fragilité et spectaculaire}

L'émotion créée par l'aspect brut de l'interprétation des jeunes comédiens, faite d'une beauté fragile et d'une touchante inégalité des niveaux de jeu, est toujours contrebalancée par un dispositif à la Broadway, articulant avec brio costumes, chansons et chorégraphies.

La fraîcheur des acteurs, qui peut sembler parfois menacée par la structure spectaculaire et les micros HF, demeure un des éléments du spectacle qui émeut le plus. Dans une forme complexe, hybride, audacieuse, colorée, où la musique est omniprésente, le naturel des amateurs est préservé. 
15 Résolument, la mise en scène audacieuse d'Arnaud Meunier constitue à bien des égards, pour le spectateur d'aujourd'hui confronté à l'afflux d'émissions commémoratives à la télévision, une expérience rare.

\section{NOTES}

1. Robert Cantarella, Carrosserie, 2004, http://www.robertcantarella.com/index.php?/film/ carrosserie/.

INDEX

Mots-clés : 11 septembre 2001, Meunier (Arnaud), Vinaver (Michel) 